\title{
Modern View on Operations Management Research
}

\author{
Andrey Blinov \\ Russian State University for the Humanities, branch in Domodedovo city \\ Domodedovo, Moscow, Russia
}

\begin{abstract}
Organizational development presents a continuous process toward a gradual, operating-sequential, ongoing management of changes, the purpose of which is improvement of organization's performance, its adaptation to changing management conditions, process-oriented rather than purpose-oriented. By now a set of concepts and models of organizational changes management has formed, applied by organizations through various approaches and practices. Application of the management consulting methods for operations diagnosis and relevant management solutions composes the key feature of the operations management. The author substantiates the necessity to revise the doctrine of today's managers training approach.
\end{abstract}

Keywords-Operations management; changes; consulting; management; business processes; diagnostics; organization; education

\section{INTRODUCTION}

Recently analysts have increased their interest in the study of operations management. Due to the turbulence of the external environment, it becomes critically important to proceed with the development of a theory of change in the economic and social systems. The question arises of how the operations management relates to the theory of change.

The operations management presents the development of managerial decisions that lead to reduced activity-based costs without the loss of quality of such activity. In this way, the operations management in the field of daily tasks is involved in a general optimization of a company's performance.

\section{MANAGING CHANGES}

Changes present; the process involving various interrelated business processes, which entails certain shifts in all sections of an organization. Its top management has to continuously monitor the major external environmental parameters and take decisions pertaining to reasonable adjustment.

In this light, the training of analysts responsible for monitoring the changing environment and evaluation of the organization's current standing towards accurate managerial decision-making becomes topical. The problem consists of streamlining the organization's performance without destroying it.

The strategy of change often underestimates the scale of alterations and impacts on the organization. Changes involve a procedure which includes various interrelated business processes, producing certain shifts in all sections of an organization.

By now, we have a set of concepts and models of organizational changes management that businesses carry out through various approaches and practices.

Generally speaking, in spite of many techniques suggested by the contemporary theory of operations management, there are just two key polar approaches to the changing of management - the 'subtle', evolutionary, and the 'hard-line', revolutionary.

These approaches apply to managing changes of two basic types - the incremental (gradual process) and a quantum-like jump. Business development pertains to 'subtle' practices, while the 'hard-line', revolutionary, practices, based on the process approach, means the reengineering of the business process; the methods of change, such as reengineering or enterprise virtualization, can be assigned to different groups.

\section{ORGANIZATION DEVELOPMENT CONCEPT}

There is the organization development concept, which has been offered by E. Mayo and F. Roethlisberger [7].

The essence of an organization's development reduces to a deliberate, gradual and across-the-board change of corporate culture towards the adjustment of business to a rapidly changing external environment against increased productivity and quality of work. All changes are executed 'bottom-up'. Such approach puts the prime focus on the human factor. Business managers are in a greater or lesser degree oriented to the training and development of their own staff. Such a method implies planning, initialization and implementation of the change process specifically in an organization's social component e.g. its corporate culture. It is expected that an organization will be changing through the alteration of the views, values and behavioral patterns of its personnel; its training and career enhancement are expected to raise the labor productivity along with the organization's effectiveness in general. The behavioral science achievements form the major theoretical foundation for managing changes.

Consequently, it may be concluded that the business development offers a continuous process toward a gradual, operating-sequential and on-going management of changes aimed at the improvement of an organization's performance; 
its alignment toward the changing conditions of management should be oriented to the process, rather than to the purpose.

D. Miller, P. Friesen, M. Hammer, J. Champy and others have studied changes from the 'hard-line' approach position, such as the 'quantum-like jump'. The reengineering offers technology that boosts an organization's strength based on the change of its operational processes and adjustment to or replacement of the applied business model [8]. Miller and Friesen are describing changes in organizations as a "quantum-like jump", which means - in contrast to changes 'piece by piece', when one component changes in a successive order - a simultaneous change of the set of organizational components. The 'hard-line', jittery, reforms are the most distinctive for large, established and diversified organizations, wherein all processes and procedures are being standardized and regulated, and this is the main obstacle and deterrent to a changes execution. That is why such organizations stagnate repeatedly and continuously.

At the same time, such spikes lead to an across-the-board reengineering of all processes, pushing organization to a completely new level in its development. The organization reshapes all its existing methods, approaches to business management, and invents brand new ways and principles of operations management. Moreover, the need in it arises only in the case of it feeling necessary for profound changes. This method must be oriented toward the latest technologies and human resources. Business management targeted to changes and the minimization of operational costs implies the application of methods based on the process approach, including the 'Just-in-Time' and TQM (Total Quality Management) [1]. The TQM principal, widely practiced in Japan from the mid 50's, suggests the partaking of all members of the workforce in upgrading products and services, achieved through a continuous in-house training of the personnel. The advantage of such a principle is the high quality of the products is ensured by the systemic employee involvement at all levels in the development and management of organizational changes, as well as by all process operations in the organization, bound by a shared purpose - the product or service development. The 'Just-inTime' principle provides for such engineering that practically does not require storage of intermediate and finished products, and ensures a considerable lowering of the unreasonable consumption of resources.

We should classify and flag the primary advantages and deficiencies in the above-described principles of and approaches to the organizational adjustment [3].

The business development. Advantages-Advantages include the high social adaptation to changes, a low-level resistance to changes, its evolutionary nature, the focus on the 'human factor' and the workforce capacity, employee training, education, and their continuous development, which facilitate the labor productivity and business' selfimprovement, Furthermore, advantages include the raised motivation and initiative of personnel involvement in changes though their active engagement in the process, and a continuous, progressive and gradual introduction of changes providing for high adaptively to a rapidly changing environment. Deficiencies-The slow change implementation, preponderance of the social factor, a weak feasibility of unpopular but indispensable ideas, the impossibility of applying the adjustment to changes at certain stages of development operations, the need in external consulting organizations, and the required compromises in change management all present possible problems.

Reengineering of business processes [3], [5]. Advantages-Advantages include the rapid and radical replace ability of an organization's management, the potential of an organization's considerable improvement in efficiency within a short time, the development of landmark working techniques and practices, the conceptual consistency of events, and the considerable expansion of personnel competency when changing from functional departments to stand alone process teams, which saves time spent on numerous consensus-building needs among the departments. Further advantages are a creative approach and ownership in decision-making, increased flexibility, and free choice in the process of changing management. DeficienciesDeficiencies include staff reduction, goals occasionally remaining unachieved, time and procedure limits due to the ambition of attaining the object as soon as is practicable, the underestimation of the 'human factor', bias towards the process-oriented component, and a low social acceptability that results in an increased opposition. Finally, other negatives include the uncompromising attitude when reengineering from the 'top down', procedures' high labor intensity, and the requiring of employees' special competence and high skills.

\section{Human Resource Management}

Organizations are in constant search for new ideas and fresh approaches, which implies the need for new people, who can make it. Contemporary business is in a dire need of specialists capable of creative undertakings, who can act as generators of unconventional ideas. This refers to workingout of special programs on development of corporate talents. During the course of managing changes, it is of a paramount importance to resort to the personnel's creativity - after all, the creative approach to business management forms the innovative development base. The following way of describing the creative potential can be conditionally given under managing changes in an organization. It is built upon the natural consequence of applying the divergent and convergent thinking.

Employees' creative potential amounts to the ability and commitment to overcome difficulties and address set problems. This refers to the motivated and unmotivated approaches. In the first instance, the creative potential draws on the expertise, method selection, social criteria, cultural universals, etc. In the second instance, the expertise does not play such a crucial role and so, the process of applying the creative potential becomes intuitive and goes through trial and error. A definite problem solution presents a conflict between what there is and what an organization needs to carry out for successful changes. Such a conflict comprises, on the one hand, an internal incentive to mobilize each employee's creative potential, and, on the other hand, the 
push for external activity in solving the problems of changing the organization. Employee's personal creative fulfillment, as an individual and subjective vision of his or her needs and their satisfaction, lies within themselves and is brought outwards through personal fulfillment. Each collective employee's creative potential is fulfilled only if that aspect, which is identical to his or her organization's need at large. Organizational changes hinge on the use and development of its members' creative potential. To be able to hold full responsibility for both its purpose and performance, the business must have the knowledge of how to use its human resources' creativity, and how to assess it.

Performing his or her daily duties, the manager interacts with various groups of people. First, they are referred to partners. Sometimes they can be completely disagreeable, make absurd or even threatening demands, yet, in any event, communication with them has to be civil, without one's display of irritation. Another group of people with whom the manager is communicating, includes a variety of other different managers. While in contact with them, he or she has to express themselves plainly and explicitly, sticking to the facts or their own considerations, and put ideas succinctly. While describing a particular problem, he or she better promptly suggest his or her solution, so their boss does not need to address the issue from start to finish. Generally, it is better to take the laboring oar on oneself - the boss will not forget this. Contacts with subordinates should be extremely trust-based and benevolent, because, as we know, the manager's lot largely depends on the latter. Finally, the manager regularly connects with his fellow managers of other branches. He has no direct influence on them and particular negotiating, bargaining and convincing skills are required here from him.

A contemporary business manager is expected to possess:

- Competence to influence and change the organization;

- Capacity to build up a team;

- Competence to improve the efficiency of their department;

- Skills to develop their department within the organization.

\section{Management Consulting APPROACH}

The application of management consulting methods to diagnose operations and offer relevant management solutions presents the key feature of the operations management. In this context, it is essential to spearhead the formation of an internal consulting department in an organization.

What are the main principles of establishing the department of internal consulting? Its objective is the competitive growth of the business, based on consulting management, that is, the corporate governance with the help of knowledge and skills of professional consultants on internal consulting [1]. Possession of a complete market and internal information can refer in this context to a competitive position.
The key tasks of the management advisory department can be divided into operational and strategic.

Operational objectives:

- Data collection and analysis of all departments' activities:

- Development of proposals on alignment of the departments' activity management;

- Daily performance consulting of the departments' employees;

- Review and drafting of proposals for top managers in an effort to align the design of internal corporate structure;

- Control over consultants' carried out solutions (direct consulting);

- Appraisal of the process of execution of any approved solutions, insight, implications, future references.

Strategic objectives of the management consulting:

- Review of the commodity market;

- Drawing up (or adjustment) of corporate competitive market strategy;

- Counseling on introduction of amendments to the corporate competitive strategy;

- Analysis of economic situation in case of taking such action (business planning);

- Attraction of external consultants, their hire, contracting etc.;

- Attraction of skilled staff needed for development of a better internal management system;

- Appraisal of the implementation of any approved solutions, future references.

Perhaps the overarching role of the management consulting department amounts to strategic problem solving; however, that is not quite the case. The point is to make a shrewd guess at the vector of market changes, market demand and buyers' needs. For this very reason, the management consulting department has to combine two vital functions - the work of present-day problems and the development of a business strategy.

It should be emphasized that the performance of the management consulting department suggests a clearly stated cyclicality: working-out, designing, implementation, control; these cycles, though time-stretched, constantly resume, mindful that upon completion of one project, another one is launched.

In summary, the department has to deal with the presentday and strategic problems side by side. Otherwise, the overall operational efficiency is bound to slump. Absence of a sober estimate of the corporate structure's capacity and standing makes it impossible to develop a viable business- 
plan. With no study of market features, it is impossible to arrange an ideal business framework.

The management consulting department must include four professional consultants:

- Corporate manager;

- Analyst manager;

- Financial manager;

- Psychologist-manager.

Each field can be managed by several specialists - both permanent and external, noncore consultants. Their number depends on the amount of data for analysis and, of course, on the size of business.

The corporate manager determines corporate market strategy and presents the pivot of the management consulting department. Their basic focus is on the external market environment: finding vacant market niches, identifying rivals and their watch, and developing opportunity products. Fundamentally, this department's functions are similar to those of a marketing department. Its distinction consists in high-caliber professionals, who work there and are in position to consult only, not manage. They resort to external consulting on all market problems requiring extra information. The corporate manager possesses the best and credible information on performance of all corporate departments and is well aware of his company's actual possibilities and its internal structural weakness. He or she do not focus their efforts on the sales of present goods and services, and works long-term trying to foresee future demands of the market, such as its direction and progress trends. This, in essence, is the core task of internal consulting.

Responsibilities of the corporate management unit:

- Make recommendations to senior members of the company's perspective markets, their geographical location and goods to be offered; inform on particular business direction, which investment strategies to continue, what company activities should be closed, and what new directions must be developed and financed;

- Identification and mapping-out of purpose market fractions;

- Study of targets and priorities on a selected market segment;

- Development of marketing proposals;

- Contact with all company departments;

- Regulation, consulting and supervision over adequate task execution and the business performance at large.

Executives of the management consulting department are armed with the internal market data, on the one hand, and with the know of the business' internal state. Using these insights, the department can model its company's market strategy. The next step requires the involvement of experts from other departments and units for further setting of tasks.
The analyst-manager processes information compiled from all branches of the organization. Analytic treatment comprises proposals coming from other units of the management consulting department. Such activity area is essential for a more in-depth and professional analysis of present problems and situations in order to avoid decision errors.

The financial manager analyses the financial position of the business by consulting the financial and accounting departments and engages external consultants of different specializations. Their priority is the partnership and contact with the internal manager on project development and its execution.

The psychologist-manager. Headhunting and recruitment, employees' alignment to new environment, revision of the incentive and reward system should be especially accurate here.

The manager's responsibilities include:

- Framing of the internal corporate structure, including rules, standards of behavior, and division of power;

- Recruitment, professional development with the use of trainings, external coaching;

- Development of corporate philosophy, identity and code, team development and development of corporate spirit;

- Monitoring and regulation of company's internal structure given future production plan updates, determining project managers and project advisers.

Administration of decision implementation: Manager's tendency to build relationship with in-house consultants from the position of "I'm the boss-you're inferior" presents the common problem in managing changes in an organization that uses resources of the internal consulting structure. And if not from the first days of work, this is bound to happen afterwards, since it is not easy to abandon the stereotypes of system behavior and relationships. The internal consultation cannot lead to positive solutions against such a system of relationship. It is essential to redefine the relations with subordinate internal consultant on equal footing.

Internal consultants, obviously, require extreme ethics, self-discipline, competence and high responsibility for their recommended and carried out changes.

At the same time, internal consultants, thinking outside their habits, likes and dislikes, have to learn to assess the existing situation with maximum objectiveness. They have to come down to the position of corporate clients and discuss topics as clients.

This is where competence of the internal consulting department presents their skill in compromise [2]:

- Between the execution of a necessary action plan and its actual perception both by top managers and the manager, who begins to doubt the plan under the influence of the top managers who assert their interests (and selfish motives among others); 
- Between the readiness to retain normal relationship in the organization, engaging key employees in developments, and the necessity to hold ground and carry out changes consistently and steadily;

- Between the desire to retain top manager's disposition and the necessity to pinpoint existing current deficiencies in the business, to revise principles and approaches, which oftentimes the manager receives very painfully, though the information was presented accurately;

- Between the intention to attain the desired effect through sequential actions and the continuing need to compromise for the sake of the same incremental systemic change;

- Between the factual constraint to relinquish the chosen tactics and the problem of fulfilling the strategic tasks.

Though it is impossible to avoid certain antagonism, since the very human nature is conservative, yet it is essential to attempt to minimize it, recognizing, before everything else, the root cause of such aversion.

To minimize the pushback to raise the effectiveness of the reorganization the following are required:

- Specify the purpose and intent of the organization development, clear it through and approve with top manager (owner) and managerial apparatus;

- Supply the parties to changes with information on the purpose and result of the intended changes;

- Set up a work team to arrange and execute changes, including top managers who are in good standing with their workfellows. What is more, both processes of approval and execution must engage leaders without formal authority;

- Attach a special status to the work team with ample authority;

- Work out the system that would ensure and manage changes, assisting the planned development and execution of the control over changes and over the organization at large;

- Generate the criteria of attaining the reorganization goals;

- Ensure the development budget;

- Determine stages of reorganization and attain approval from managers of departments concerned;

- Assist the reengineering by developing and introducing new incentive programs.

\section{CONCLUSION}

Considering the aforementioned, there arises an obvious need to revise the doctrine of contemporary managers training [4].
- A systematic understanding of students' R\&D work is needed, as it offers considerable opportunities for further higher personal development. 2. It is important to include the research work educational process of universities as an advisable aspect rather than a subsidiary. 3. It is also important that the scholarly work becomes its axis, assigning a specific accent to the study of theoretical training courses and shaping the creative nature of training and internships. In this context an established guidance system of its implementation can help provisions, defined forms, directions, and organizational forms. It can compile a list of genres of scientific work and the corresponding compliance requirements, as well as sets of diagnostic techniques. Furthermore, scientific teaching aids can reveal the purpose of the research work and its logic and suggest scientific booklists. The university atmosphere should always be a state encouraging the creative competition between students: defense of research works, creativity competitions, academic competitions, professional skill competitions and such promote such activity. As a supplement, a closer attention to personal advancement of academicians is likely to be a serious step toward renewal of academic education;

- The procedure of discussions and practical training (disputes, 'debates' as contests in logic and such) have to become diverse and oriented to students' strong personal interests;

- Academicians and students have to "turn to each other", to learn from their mutual experience and empathic interaction;

- "Deeper contact" must become the stepping-stone to mutual influence;

- It is important to assist students in understanding of their value for themselves and for the community; to develop their strive for development and strengthening of the sense of self-worth;

- Academician has to demonstrate their respect for students and address their individuality;

- To acknowledge the development as progression through "bifurcation points";

- To help students experience and expand their personal subjectivity in education in a complete way, realize accomplishments as an instrument of selfcreation, take over the responsibility for a proactive finding of information, its source.

\section{REFERENCES}

[1] Revenkov A. Reengineering and Enterprise Performance // The Problems of Management Theory and Practice, 2005, №3.

[2] Blinov A. O., Dresvyannikov V. A. Management consulting. M., Dashkov \& Co. Publishing House, 2013. 
[3] Blinov A. O., Rudakov O. S., Blagireva E. N. Management of organizational changes in social and economic systems. Nauchnaya Biblioteka , 2016.

[4] Blinov A. O. Strategic mission of the economy and development of higher education // Alma mater (High School Herald), 2011, №11.

[5] Dichter S., Gagnon C. Alexander. A. Managing Change. // McKinsey News, 2003, №2.

[6] Ivancevich J. M., Donnelly J., Jr.-8rd Edition - M.: INFRA- M, 2000.

[7] Meitus V. Virtual enterprises in the 21st century society. // Information Technologies, 2005, № 6.

[8] Norbert Tom. Change Management. // The Problems of Management Theory and Practice, 1998, №1. 